\title{
LETTER FROM PROFESSOR ANSTED, ON GOLD IN WALES.
}

To the Editor of the GmoLoarsT.

Srr, -One of your correspondents in the last number of your Journal enquires about the gold of Wales. Perhaps a brief account of the matter will be generally interesting.

There can be little doubt that gold has been obtained in former times by washing the sands of several of the rivers that come down from the slate-rocks in that part of our island,* but it was not until 1843 that the $\mathrm{C}_{\mathrm{wm}}$ Hesian Mines near Dolgelly, in Merionethshire, were first noticed by Mr. Arthur Dean, as containing something like a complete system of auriferous veins. An account of this discovery was communicated at the meeting of the British Association at York, in 1844. Since that date the mines have been partially worked, and in 1853 I visited them myself, and carefilly examined the district.

The Mowddach Valley, and some of its small tributaries close to the town of Dolgelly, contain the chief mines that have been found to possess any quantity of gold. The metal occurs as usual in a native state, but is found in veins and flucany cross courses, parallel and at right angles to the porphyry range, which here runs north and south through Merionethshire. The nearest fossiliferous rocks are the Lingulabeds of the lower Silurian series, and the reins usually occur in underlying metamorphic schists. The matrix of the veins is quartzy, and the associated minerals either galena and blende, or iron and copper pyrites. In addition to the gold in the reinstone, minute particles are disseminated through the pyrites. I noticed particularly here, and have since observed elsewhere, wherever any gold was present in veins, that more or less magnesian mineral (generally chlorite or steatite) is found in the immediate vicinity. At the time of my visit one of the strings of goldbearing quartz in chloritic schist was opened, and I obtained from a few specimens of quartz, struck off whilst I was underground, very distinct threads and grains of gold; the general yield of the small quantity thus removed being at the rate of 60 ounces of gold to the ton of matrix. Further researches, however, failed to discover any quantity worth working, and the mine has, I believe, been since neglected. At Clogau, not very far off, other auriferous specimens far richer were obtained a year or two after my visit, but here, also, the works are stopped.

Generally it may be said that the gold districts of Wales are limited to those places where the rocks are not only schistose but chloritic or steatitic. They present a very marked resemblance to those of other countries where gold occurs more abundantly, but much more especially to those of the South-Eastern States of North America, where almost all the indications of the associated rocks and the minerals are precisely similar. No doubt in former times, when nearly all the rivers of Western Europe brought down appreciable quantities of gold, or at least when the accumulations of ages were still untouched, the Welsh streams, as well as the Germun, French, and Spanish rivers, were rich

- The Romans obtained gold from quartzy lumps in slaty rocks at South Gogofau, about 10 miles west of Llandovery. They also appear to have ground down the iron pyrites of the same district, which they afterwards washed for gold. 
in golden sands. These have long since been removed, whilst at the present price of labour, and with the extreme irregularity of distribution that seems always to obtain where native metals exist, it is almost a hopeless chance to expect profit from mining or reducing establishments on a large scale.

$$
\text { I am, \&c., }
$$

17 Manchester-street, 17th March, 1858.

D. T. ANSTED.

\section{NOTES AND QUERIES.}

Detremination of Fossils. -Inquirar (Harwich).- "In my district I find abundance of certain fossils, but not having any large library accessible to me, nor any learned friend to whom I could appeal, and as I cannot afford to expend much money in books-indeed, even those I possess, through my inexperience, do not afford me that certainty of determination which, as a foundation to further efforts, I so much desire-can you inform me of any ready and inexpensive means of learning their names?"-Similar difficulties in naming fossils have been made known to us, as experienced by W. H. Y. (Sherborne); T. H. (Hinckley); A. C. C. (Forfar); Student (Blyth); J. P. (Stowmarket); W. K. (Chudleigh); R. F. (T'onbridge); W. E. (Chester); Rambler (Swindon); H. P. (Ledbury); I. C. C. (Saffron Walden); A Colleotur (Felixstow). We have received such very numerous inquiries of this nature, as to make us regard this difficulty, experienced by isolated students and beginners, with much interest. If duplicate specimens are sent free to the Editor, with numbered lists and localities, addressed to the care of Mr. Allen, 2 Catherine Street, Strand, such lists will be returned as soon as convenient, with the generic and specific names insertee.

Provinclat Correspondents.-A correspondent at Worcester writes, that he thinks " local facts should be especially looked to, and every effort made to obtain the latest observations, such as might be long in getting into the Proceedings of the Geological Society, \&c. ; and to ensure this it is perhaps not enough that a number of numes appear as contributors, but that in each county or district some one or two correspondents should regularly be engaged to forward to the Editor all new facts and observations connected with their districts."-We print this extract from our correspondent's letter, because it accords with our own views and wishes, and with those which other correspondents have communicated to us. We have already commenced taking steps to obtain such a combination of workers, which, more than anything else, will tend to keep up the standard of the Grococist as a work of merit, and to maintain its name in popular favour. If the working geologists and amateurs in the country will forward to us accounts of their discoveries, we will do our best at all times, in this great city, where the best can be done, to render their labours available for the progress of science. We should be pleased to have regular correspondents in every district; but these, of course, must be voluntary helpers, as our resources would not permit wuch a staff of paid contributors. The correspondent at Worcester from whom we have quoted, recommends the report, in full, of the proceedings and excursions of all Hield Clubs. There is very often more conviviality than science in these meetings, and we only consider it necessary to report that which has a scientific value. We should be obliged to the seeretaries of Field Clubs or Naturalists' Associations for notices of the proceedings, as we by no means under-rate the utility and practical value of such institutions. We have no intention nor wish to anticipate the published records of the Geological Society. Very little, we think, of importance escapes a ready 